\title{
Activated temperature of coal gangue and its effect on mechanical properties of cement mortar
}

\author{
Bingke Qin ${ }^{1,2, a}$, Yonghua Ji ${ }^{1, b}$, Zhiling Bai ${ }^{1, c}$, Youde Wang ${ }^{1, d}$, \\ ${ }^{1}$ School of Chemistry and materials Engineering, Liupanshui Normal University, Liupanshui, China \\ ${ }^{2}$ College of Materials and Metallurgy, Guizhou University, Guiyang, China \\ aqinbingke@126.coml, bhaizhigong@126.com, czhilingbai@126.com, dkr2012@126.com
}

\begin{abstract}
Keywords: Coal gangue; Activation temperature; Mechanical properties; Component analysis
Abstract. The phase and composition of Liupanshui gangue are tested by XRD and XRF respectively. The activation properties of coal gangue as cement admixture at different calcination temperatures are investigated. The results show that: Liupanshui coal gangue as a binder to join the cement cementing material, its optimum calcination temperature is $600^{\circ} \mathrm{C}$ and the best dosage of coal gangue calcined is $30 \%$. When the coal gangue activation temperature at $600{ }^{\circ} \mathrm{C}$, the incorporation amount is $30 \%$, the $28 \mathrm{~d}$ compressive strength of cement mortar is $59.2 \mathrm{MPa}$, and the maximum flexural strength is 10MPa.
\end{abstract}

\section{Introduction}

Coal gangue is the iste produced during the coal ishing process, Liupanshui is known as "Jiangnan Sea of Coal," is the largest coal base resources in Southern China, where the annual emissions of hundreds of millions of tons of coal gangue, the stacking become a iste rock take up a lot of arable land, the local soil, water and other pollution [1-4]. If the coal gangue automatic burned will cause serious pollution to the atmosphere, and undermine the healthy development of the ecological environment. It has become one of the important research directions of coal measures solid waste for the comprehensive utilization of coal gangue in the process of turning waste into treasure.

In this paper, according to the current research progress of coal gangue utilization, coal gangue used in cement concrete, must be activated, otherwise it will cement the performance of the cement material caused by adverse effects. There are many ways to activate coal gangue, there are three kinds of mechanical activation, heat activation and chemical activation of three kinds of heat activation of coal gangue calcined, the coal gangue calcined with the nature of volcanic ash and have a certain degree of gelatin, can be part of the alternative Cement is used as a binder for cementations materials [5]. So the heat activation of coal gangue is three kinds of activation which is more effective and commonly used method. Each place of coal gangue composition and physical and chemical properties are different. Therefore, the heat treatment technology of cement gangue in Liupanshui mining area is studied systematically[6], which fully stimulates the activity of coal gangue, and makes full use of local coal gangue to solve the problem of coal gangue application and Pollution has a guiding significance.

\section{Experiment}

The cement was made of ordinary Portland cement on the local market, labeled P• O32.5 R grade cement; sand was a local common stone sand over $5 \mathrm{~mm}$ sieve. The coal gangue from Liupanshui Eagle Hill mining area. The water used to place more than $24 \mathrm{~h}$ of tap water.

The X-ray diffract meter and XRF spectrometer are used to detect the phase and composition of coal gangue. Coal gangue after self medium separator separates the poor mechanical property of coal gangue, better mechanical property of coal gangue after washing for standby, the sediment after drying and poor mechanical properties of coal gangue in XL-1 furnace in calcination, the range of calcination temperature is $400{ }^{\circ} \mathrm{C} \sim 800{ }^{\circ} \mathrm{C}$, coal gangue calcined after ball mill grinding, grinding into fineness of 200 mesh powder, according to a certain proportion of cement cementing material. 
Mixed with heat activated coal gangue cement mortar strength determination, after heat activated coal gangue with different content (mass fraction) into the cement mortar, and in accordance with GB / T 17617-1999 "cement mortar strength test Method (ISO method) "to carry out the formation and maintenance of the specimen, the use of WAW-600C universal testing machine to test the mechanical properties of cement mortar specimens.

\section{Results and discussion}

Composition and phase analysis of coal gangue. Table. 1 shows the results of XRF of raw coal gangue. The results show that the main components of coal gangue are quartz, iron and aluminum oxide, which account for nearly $80 \%$ of coal gangue. In addition, that Liupanshui coal gangue also contains a few amount of titanium.

Table.1 Analysis of main elements of coal gangue by XRF

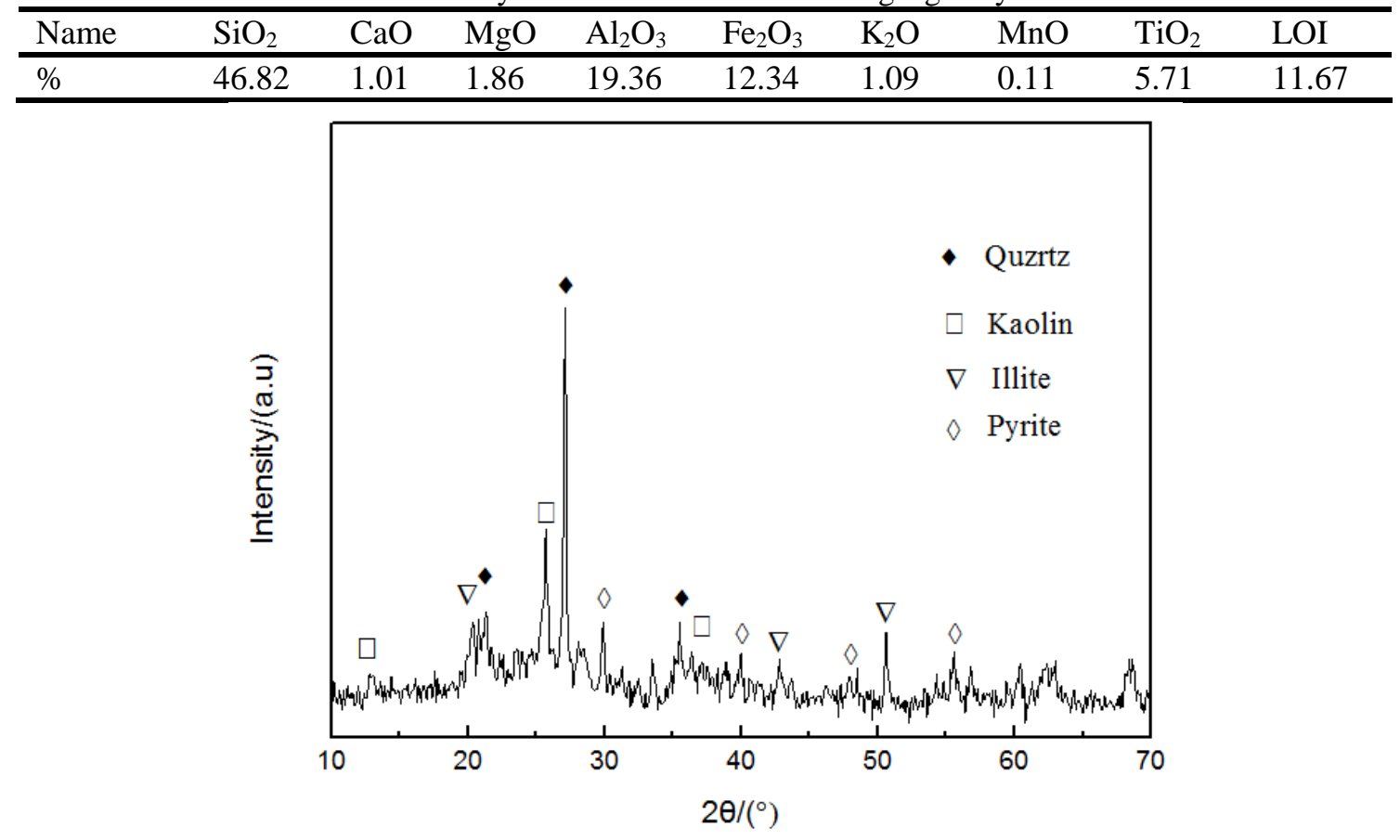

Fig.1 XRD patterns of raw coal gangue powder

Fig. 1 showed the gangue XRD test pattern, the scanning step is 0.1 , the scanning angle range is $10^{\circ} \sim 70^{\circ}$. The analysis of the mineralogical phase shows that the main components of coal gangue are quartz, kaolinite, and a small amount of illite and pyrite and some organic matter. Gangue at high temperatures, will make kaolinite, pyrite and organic matter decomposition, thereby changing the original mineral composition of coal gangue, and improve the activity of coal gangue [7].

The effect of calcination temperature on the activity of coal gangue. In the calcination process, the kaolinite where content in the coal gangue at about $500{ }^{\circ} \mathrm{C}$, will be occurrence of inter-layer hydroxyl dehydration in the conversion into amorphous met kaolin. In the stage of $500{ }^{\circ} \mathrm{C} \sim 744.4{ }^{\circ} \mathrm{C}$, the exothermic reaction of organic matter, the exothermic reaction of pyrite and the decomposition endotherm of kaolinite are studied[7,8]. Therefore, the calcination temperature range of this study is $400{ }^{\circ} \mathrm{C} \sim 800^{\circ} \mathrm{C}$.

Under the conditions of water-cement ratio of 0.36 and coal gangue content accounting for $30 \%$ (weight ratio) of cement, the effects of the heat activation temperature of $400{ }^{\circ} \mathrm{C}, 500{ }^{\circ} \mathrm{C}, 600{ }^{\circ} \mathrm{C}$ and $800{ }^{\circ} \mathrm{C}$ on the cement Effect of mechanical properties of cementitious materials. The test of compressive strength and bending resistance of the specimen is shown in Table 2 and Table 3 . It can be seen from Table 2 that with the increase of activation temperature, the compressive strength of coal gangue cement samples decreased at $3 \mathrm{~d}$ and $7 \mathrm{~d}$, and the compressive strength of 28 days is improved 
to some extent. At the activation temperature of $800{ }^{\circ} \mathrm{C}$, the compressive strength of $28 \mathrm{~d}$ reached the maximum, the maximum value is $65.4 \mathrm{MPa}$.

Table 2. Compressive strength of coal gangue cement mortar at different activation temperatures

\begin{tabular}{ccccc}
\hline Activation temperature $\left({ }^{\circ} \mathrm{C}\right)$ & 400 & 500 & 600 & 800 \\
\hline $3 \mathrm{~d}(\mathrm{MPa})$ & 43.0 & 41.0 & 39.5 & 41.0 \\
$7 \mathrm{~d}(\mathrm{MPa})$ & 46.0 & 44.2 & 43.5 & 51.0 \\
$28 \mathrm{~d}(\mathrm{MPa})$ & 57.1 & 57.0 & 59.2 & 65.4 \\
\hline
\end{tabular}

When the amount of heat activated coal gangue is $30 \%$, the flexural strength of coal gangue cement sample is shown in Table 3. It can be seen from the data in the table that the addition of heat activated coal gangue to the pre-bending strength Almost no effect, with the extension of time, $7 \mathrm{~d}$ and $28 \mathrm{~d}$ flexural strength with the activation temperature fluctuations have fluctuated, the overall increase in the trend. When the activation temperature of the coal gangue cement is above $600{ }^{\circ} \mathrm{C}$, the flexural strength of the coal gangue cement reaches 10MPa.

Table 3 different activation temperature of coal gangue cement mortar flexural strength

\begin{tabular}{ccccc}
\hline Activation temperature $\left({ }^{\circ} \mathrm{C}\right)$ & 400 & 500 & 600 & 800 \\
\hline $3 \mathrm{~d}(\mathrm{MPa})$ & 7.0 & 7.0 & 7.0 & 7.0 \\
$7 \mathrm{~d}(\mathrm{MPa})$ & 8.0 & 7.0 & 8.0 & 9.0 \\
$28 \mathrm{~d}(\mathrm{MPa})$ & 9.0 & 7.0 & 10.0 & 10.0 \\
\hline
\end{tabular}

Through the above analysis, coal gangue activation temperature above $600{ }^{\circ} \mathrm{C}$, which can better stimulate the activity of coal gangue. Although the activation temperature is favorable to further improve the mechanical properties of the sample, considering the high activation temperature of coal gangue will cause the cost increase, so the best activation temperature of heat activated coal gangue is $600{ }^{\circ} \mathrm{C}$.

Table 4. Compressive strength test of cement mortar with different coal gangue content

\begin{tabular}{ccccccc}
\hline $\begin{array}{c}\text { Amount of coal } \\
\text { gangue (\%) }\end{array}$ & 20 & 25 & 30 & 50 & 70 & 90 \\
\hline $3 \mathrm{~d}(\mathrm{MPa})$ & 34.5 & 31.5 & 39.5 & 3.7 & 4.9 & 5.4 \\
$7 \mathrm{~d}(\mathrm{MPa})$ & 36.5 & 32.5 & 43.5 & 7.46 & 7.0 & 7.5 \\
$28 \mathrm{~d}(\mathrm{MPa})$ & 38.1 & 38.6 & 59.2 & 21.2 & 16.4 & 13.1 \\
\hline
\end{tabular}

Table 5. Test results of flexural strength of cement mortar with different coal gangue content

\begin{tabular}{ccccccc}
\hline $\begin{array}{c}\text { Amount of coal } \\
\text { gangue }(\%)\end{array}$ & 20 & 25 & 30 & 50 & 70 & 90 \\
\hline $3 \mathrm{~d}(\mathrm{MPa})$ & 5.0 & 7.0 & 7.0 & 2.3 & 2.0 & 2.0 \\
$7 \mathrm{~d}(\mathrm{MPa})$ & 7.0 & 7.0 & 8.0 & 3.8 & 3.0 & 3.4 \\
$28 \mathrm{~d}(\mathrm{MPa})$ & 8.0 & 7.0 & 10.0 & 7.2 & 6.5 & 5.2 \\
\hline
\end{tabular}

The best amount of heat activated coal gangue in cement mortar. In the case of water - cement ratio of 0.36 , the activation temperature of coal gangue is $600{ }^{\circ} \mathrm{C}$, and the influence of coal gangue content on the mechanical properties of cement cementing material is examined. The results of the test are shown in Table 4 and Table 5, respectively. After the standard curing, the compressive and flexural properties of the coal gangue cement are tested. From the test results, it can be seen that the compressive strength of the sample increases with the increase of the amount of coal gangue before 
$30 \%$. When the amount of coal gangue incorporation is $30 \%$, the maximum compressive strength and flexural strength of the sample are the largest at 28 days, which are $59.2 \mathrm{MPa}$ and $10 \mathrm{MPa}$ respectively. When the amount of calcined coal gangue is more than $50 \%$, the compressive strength of the specimen decreases sharply, and the mechanical properties of the sample are significantly worse. Through the comprehensive analysis of the experimental results, the optimum dosage of gangue activation temperature is $600{ }^{\circ} \mathrm{C}$.

\section{Conclusions}

The coal gangue in Liupanshui mining area is sorted by different mechanical properties, the optimum temperature of thermal activation is $600^{\circ} \mathrm{C}$ and the holding time is $2 \mathrm{~h}$. The calcined coal gangue are milled for 200 purpose powder, can be used as admixture of cement cementitious materials. When the incorporation amount is less than $30 \%$, the mechanical properties of cement mortar had a little affected, the compressive strength is slightly decreased in the early stage, and the compressive strength at the later stage is slightly increased. The mechanical properties of cement bonded sand samples rapidly became worse after the addition of more than $30 \%$. When the activation temperature of coal gangue is $600{ }^{\circ} \mathrm{C}$ and the content is $30 \%$, the compressive strength of cement mortar is $59.2 \mathrm{MPa}$ and the flexural strength reaches $10 \mathrm{MPa}$.

\section{Acknowledgements}

This study has been supported by the Guizhou provincial science and technology department joint fundation (Qiankehe Jzi LKLS [2013]19); Guizhou province ordinary college innovation team of mineral processing and comprehensive utilization of scientific and technological (Qianjiaohe Talent team zi[2015] 69); Guizhou provincial department of education fund project (QianjiaoheKYzi[2016]102); Guizhou province ordinary college innovation team of coal solid waste recycling technology (Qianjiaohe Talent team zi [2014]46).

\section{References}

[1] X.M.Duan,J.W.Xia,J.P.Yang: Jianzhu Cailiao Xuebao Vol.17 (2014),P.700-705.

[2] Jianhong Lei: Energy and energy conservation vol.4(2017),P.90-91. In Chinese.

[3] Ning Liu,Kaiping Liu,Lijuan Rong: China concrete and cement product Vol.9(2012),P.74-76. In Chinese.

[4] Yanzhi Cao,Shaoqing Guo,Jindong Zhai: Coal geology \& Exploration Vol.45(2017),P.26-29. In Chinese.

[5] Xiujun Guo: Coal engineering Vol.49(2016),P.74-76. In Chinese.

[6] Chao Li,Liang Zhao,Xiaomei Hui et al: Chinese Journal of Environmental Engineering Vol.11(2017),P.4349-4353. In Chinese.

[7] Deshun Kong,Zhi Li,Jiaxin Fan et al: Coal Engineering Vol.7(2013),P.99-101. In Chinese.

[8] Zhao Cao,Yongdan Cao,Hongjuan Dong.et al: International Journal of Mineral Processing Vol.146 (2016) ,P.23-28. 